\title{
The Effects of World Heritage Listing on Tourism to Australian National Parks
}

\author{
Ralf Buckley \\ International Centre for Ecotourism Research, Griffith University, \\ Parklands Drive, Southport 4215, Australia
}

\begin{abstract}
A time series of historical visitor data was used to test whether World Heritage Area (WHA) listing affected the total number or origins of visitors to Australian national parks. Only six of Australia's 14 WHAs have sufficient data to attempt such tests, and these data have significant shortcomings. Whilst visitor numbers at Australian WHA's are commonly up to an order of magnitude higher than at comparable control sites, this cannot necessarily be ascribed specifically to WH branding, but may be associated more with political controversy over listing. It does, however, appear that WH designation yields significant increases in proportions of international visitors to individual sites.
\end{abstract}

Keywords: national parks, heritage, economic value, visitation, policy

\section{Introduction}

Does designating a site as of World Heritage status alter who visits it? This question is significant for many reasons and for many stakeholders. Site managers may have more people to provide for, perhaps with different interests and languages. Tour operators may gain new or different commercialopportunities. Local residents and regional economies may benefit from increased tourist expenditure. And conservation policy makers may use tourism benefits as one justification for heritage listing.

World Heritage designation is not intended as a tourism marketing device, but it may work that way. Under Article 2 of the World Heritage Convention (UNESCO, 1972) the criterion for listing is 'outstanding universal value' from scientific, conservation or aesthetic viewpoints. This is reiterated and expanded in Clauses 43-5 of the Operational Guidelines (UNESCO, 1998), which cover 'criteria for inclusion of natural properties in the World Heritage List'. Signatory nations are required to report periodically on their application of the World Heritage Convention, and under the Explanatory Notes to the Operational Guidelines, Article II, 5 (UNESCO, 2000), these reports should include 'visitor/tourism pressure', as a potential threat.

From a tourism perspective, however, World Heritage designation acts as an international top brand in nature tourism, and perhaps also as a collectable set. It is commonplace for tour operators using World Heritage areas to advertise that fact. World Heritage designation may therefore increase the number of tourists who visit a site and the amounts they spend; but this is by no means certain.

The question is controversial because of differing stakeholder interests; some in favour of listing and some against. From the perspective of many stake- 
holders, it is arguable whether sites gain or lose from World Heritage listing. For conservation interests, there are concerns that recognition of outstanding universal value will provoke increases in visitor numbers and impacts that ultimately reduce those values. For local residents not themselves involved in tourism, there may be concern over social impacts and competition for recreational amenity. The question is also difficult to answer, for two main reasons. Firstly, there are severe limitations in historical data on visitor numbers, demographics and expenditure. Secondly, World Heritage designation is only one of many factors influencing visitation and expenditure at particular sites, and there are several sources of uncertainty in attempting to tease out its particular contribution. Broadly, either a revealed-preference or a stated-preference approach can be used. Stated-preference approaches rely on questioning visitors to establish how they decide where to go and what to spend, and using this information to partition overall expenditure between different contributing factors such as World Heritage listing. The major weakness is that people may not provide accurate information. Revealed-preference approaches, in contrast, compile data on what visitors have actually done and spent, using comparisons between listed and control sites to deduce the significance of World Heritage designation in visitor behaviour. The main limitations are weaknesses in historical data, and the general lack of truly comparable control sites. In this study a revealed-preference approach was applied to World Heritage areas (WHAs) in Australia.

\section{Methodology}

\section{Approach}

The critical issue was to distinguish the marginal contribution of World Heritage listing to tourism, additional to the level of tourism activity which would occur without listing. Conceptually, this simply requires a comparison of the economic value of tourism at sites before and after they were designated as World Heritage, and at similar but unlisted sites over the same time period. Data from unlisted control sites are needed since visitor numbers at WHAs may be affected by a wide range of economic, logistic and market factors as well as World Heritage listing itself. Some of these factors, such as large-scale economic upturns and downturns, changes in oil prices, pilots' strikes, or major national tourism marketing campaigns, are likely to affect both listed and control sites equally. Short-term peaks and troughs in visitor trend lines which occur simultaneously at control sites as well as WHAs, therefore, are unlikely to be due to World Heritage listing. Comparing listed and control sites can therefore help to distinguish the effect of World Heritage status from the many other large-scale factors which may influence visitor numbers and origins. This is particularly critical if there have indeed been significant historical changes in visitor growth rates at WHAs, at or around listing dates. If similar changes occurred at control sites, then the effect cannot be attributed to World Heritage listing. There are a number of significant difficulties, however, in applying this approach in practice. Some of these are theoretical and some practical. They are outlined below. 


\section{Treatment allocation, attribute bundling and imperfect controls}

From a statisticaldesign perspective, World Heritage listing is equivalent to an experimental treatment which is applied, at a particular point in time, to some (listed) sites but not to other (control) sites: this is a BACI (Before-After Control-Impact) design. For statistical validity, the 'treatment' of listing should be allocated randomly among sites. In reality, however, it is not: World Heritage designation is granted only to sites of the highest natural and cultural value. At least notionally, therefore, there may be systematic differences in heritage value between listed and control sites. Hence there may be more tourism at listed sites simply because they are more attractive for tourists, not specifically because they are branded as World Heritage. Our approach hence examines the overall effect of World Heritage designation as a bundle of attributes which includes heritage value, branding, marketing and often increased infrastructure funding. It does not separate out the branding effect alone. Since World Heritage listing processes and management practices are specifically designed to keep these attributes bundled, however, it is this bundled test which is most valuable for both economic and policy considerations. To minimise the effect of non-random treatment allocation, the control sites should be as similar as possible to the listed sites. In practice, however, heritage sites and other protected areas are all different, because each has a different history of land tenure and land use. The differences between World Heritage Areas and their nearest unlisted analogues can hence be quite considerable.

\section{Economic value, estimation techniques and surrogate data}

Economic value is a broad term. Distinctions may be drawn, for example, between: social economic value, regional economic impact, and direct cash expenditure; local, national and global effects; and between cash and in-kind expenditures, including time. The value of visiting a World Heritage site or other protected area, for the individuals making the visits, is commonly much higher than any entrance and activity fees which may be charged directly, and the aggregate value can be estimated using travel-cost approaches (Loomis \& Walsh 1997; Moisey, 2002; Ward, 1999). Local businesses, however, are commonly more interested in local cash expenditure, which may be linked only loosely to travel costs. For quantitative economic analysis, the type of economic value under consideration must be defined precisely. The first step, however, is to test whether World Heritage listing has any significant effect at all, and this is the approach taken here.

Since we do not have historical or even current data on the individual expenditures of each visitor, some form of estimation is required. Generally this involves dividing the tourists into a number of discrete categories with different expenditure patterns, and estimating the per capita expenditure in each category, and the proportional distribution of visitors across categories. The simplest criterion is travel distance, divided into broad zones, though there are complexities associated with multi-destination journeys. Broadly, however, this approach requires data on the total number of visitors to a site, their points or zones of origin, and the all-inclusive cost of travel from each origin zone to the destination site. 


\section{Practical data limitations and uncertainties}

For many sites, historical time series of visitor numbers are lacking or highly incomplete, and data on visitor origins and expenditure even more so. In any event, time series for both pre- and post- World Heritage listing can only be available for sites which were listed some years ago, e.g. at least 5-10 years. Some sites do not record visitor numbers even now. Some sites have multiple sources of data on visitor numbers and origins, and these rarely agree. There is hence significant uncertainty associated with missing or unreliable data. In practice, the only parameters commonly available for Australian WHAs are (1) total visitor numbers; and (2) the proportion of international visitors.

Data were obtained from reports, databases and personal communications from parks and tourism agencies at federal, state and local level, and from published sources where available. Multiple sources were used where possible to provide an indication of reliability. For most sites, data were incomplete and intermittent. For some WHAs, total visitor numbers were available only by summing data from multiple subsites or entry points. At some, visitor monitoring techniques changed over time, e.g. from automatic vehicle counters to staffed entry booths, with different errors and biases. Different areas recorded either total visits, total visitors, or total visitor days. Detailed on-ground visitor surveys were available for many of the sites, but only at sporadic intervals. In addition, many covered only short time periods, not necessarily during peak visitation. For some WHAs, data on international visitor numbers were also routinely compiled in the International Visitor Survey (IVS) by the Bureau of Tourism Research (BTR, 2003), but often these were very different from the results of on-ground surveys.

\section{Statistical difficulties}

In addition to deficiencies in data, there were statistical difficulties in comparing the pre- and post-listing trends in visitor numbers and origins at listed and control sites. Firstly, we did not know precisely what pattern we were searching for. Were we testing for changes at the listing date itself; or prior to listing, because of associated controversy; or subsequent to listing, because of time taken for listing information to reach tourists? Were we looking for a single inflection point, where the rate of increase in total or international visitors became significantly higher and stayed at the higher rate subsequently? Or did we expect a double inflection, with a short-term increase in numbers around the listing date, but no long-term effect on growth rates? And were we testing for change in a linear growth rate, with the same absolute number of visitors added each year; or an exponential growth rate, with the same proportional increase in visitors each year? Since we did not know in advance, we had to search for patterns in the observed data and test significance a posteriori, with reduced statistical power.

Secondly, in comparing growth rates between listed and control sites, there was a practical statistical difficulty in that the WHAs typically receive many more visitors than the control sites. Some form of proportional standardisation was therefore required, but there was no single measure which is appropriate for all the various patterns and periods of data available, particularly since early historical visitor numbers at some control sites were close to zero. In practice, 
therefore, it was pointless and potentially misleading to draw conclusions from direct quantitative comparisons between growth-rate figures, however standardised, at listed and control sites.

\section{Sites and Data Sources}

\section{Sites}

Australia currently has 14 World Heritage Areas. Only six of these were listed long enough ago for both pre- and post-listing data to be available, and also have a reasonably similar control site (Table 1). These are: Fraser Island, Kakadu, Uluru-Kata Tjuta, Southwest Tasmania, Shark Bay and the Central Eastern Rainforest Reserves (CERRA). One further area, the Great Barrier Reef Marine Park, would also have been suitable for analysis except that there was no appropriate control site.

Fraser Island WHA is a large sand island off the coast of southeast Queensland. It was listed as World Heritage in 1992 after considerable and protracted controversy, following a prior history of mining and logging in some parts of the island.

Table 1 Sites and summary statistics

\begin{tabular}{|l|l|c|c|c|c|c||}
\hline \hline \multicolumn{2}{|l|}{ Sites, areas, listing date(s) } & Year & \multicolumn{2}{|c|}{$\begin{array}{r}\text { Total visitors, } \\
\text { ?000 }\end{array}$} & \multicolumn{2}{l||}{ Percentage overseas } \\
\hline WH Area & Control & & WHA & Control & WHA & Control \\
\hline Fraser Island & Moreton Island & 1986 & 160 & 50 & 8 & 0 \\
$1840 \mathrm{~km}^{2}$ & NP & 1992 & 235 & 35 & na & na \\
1992 & $198 \mathrm{~km}^{2}$ & 2000 & 320 & 75 & 30 & $\sim 0$ \\
\hline Kakadu & Lakefield NP & 1975 & $? 20$ & na & na & na \\
$1980 \mathrm{~km}^{2}$ & $5370 \mathrm{~km}^{2}$ & 1982 & 60 & na & 10 & na \\
$1981 / 87 / 92$ & & 1987 & 180 & $8 \mathrm{co}$ & 19 & $3 \mathrm{co}$ \\
& & 2000 & 200 & $8 \mathrm{co}$ & 50 & $9 \mathrm{co}$ \\
\hline Uluru-Kata Tjuta & Purnululu NP & 1961 & $\sim 5$ & na & na & na \\
$1325 \mathrm{~km}^{2}$ & $3200 \mathrm{~km}^{2}$ & 1984 & 100 & na & na & na \\
$1987 / 94$ & & 1987 & 180 & 4 & $\sim 20$ & 6 ogv \\
& & 2000 & 380 & 17 & $22 \mathrm{ogs}$ & 12 ogv \\
& & & & & $65 \mathrm{ivs}$ & \\
\hline SW Tasmania & Mt Field NP & 1972 & $>50$ & $\sim 140$ & na & na \\
$13,836 \mathrm{~km}^{2}$ & $163 \mathrm{~km}^{2}$ & 1882 & $? 270$ & $? 140$ & na & na \\
1982 & & 2000 & $>500$ & $\sim 140$ & $\sim 25$ & na \\
\hline Shark Bay & Ningaloo NP & 1991 & $? 350$ & 55 & 10 & 8 \\
$23,000 \mathrm{~km}^{2}$ & $4300 \mathrm{~km}^{2}$ & 2000 & $\sim 350$ & 135 & 41 & 36 \\
1991 & & & & & & \\
\hline CERRA & SWWA NP & 1986 & $\sim 300$ & na & $2 \mathrm{q}$ & na \\
$3100 \mathrm{~km}{ }^{2}$ & $715 \mathrm{~km}^{2}$ & 1994 & $\sim 550$ & $? 690 \mathrm{~d}$ & $6 \mathrm{q}$ & na \\
$1986 / 94$ & & 2000 & 510 & $860 \mathrm{~d}$ & $12 \mathrm{q}$ & 21 \\
\hline
\end{tabular}

$\mathrm{NP}=$ National Park; na = not available; $\mathrm{co}=$ campers only; ogv $=$ on-ground visitors only (i.e. excl. overflights); ogs = on-ground surveys; ivs = data from International Visitor Survey (BTR); $\mathrm{d}=$ visitor days (otherwise shown as visits or visitors); $\mathrm{q}=$ Queensland sector only. 
It is known for its forests, heaths, dune lakes and fresh water creeks. It has a long history of recreational4WD use, particularly by fishermen on its eastern beaches. There are private in-holdings with residential and tourist accommodation. The control site, Moreton Island National Park, is a similar but considerably smaller sand island a little further south. It is approximately one ninth the area of Fraser Island, and receives approximately one quarter as many visitors: i.e. around twice as many visitors per unit area. It is closer to the State capital city of Brisbane, and more easily accessible. Much of its terrain and vegetation is very similar to Fraser Island, including heaths, dune lakes and beaches, but it lacks such well-known tall forests and freshwater creeks.

Kakadu WHA is a large and internationally known national park in the wet-dry tropics of the Northern Territory. It is famous for wildlife and waterfalls and for its Aboriginal history and culture. It was listed in three stages, with various degrees of controversy over each. The control site, Lakefield National Park in tropical Queensland, is at similar latitude and has similar environments, but is only one quarter the size and much less well known.

Arguably one of Australia's most famous international icons, Uluru-Kata Tjuta WHA is by far the most heavily visited national park in the country's central arid zone. Purnululu National Park, (NP), the control site, is also famous for red rock formations surrounded by sand dunes. It lies further north and west, in the southeastern Kimberley region, at a similar distance from the nearest large city. Purnululu NP is 2.5 times as big as Uluru WHA, but receives only one twenty-fifth as many visitors on the ground. It is somewhat unusual in that many visitors see the park only from the air, typically through early-morning or late-afternoon overflights.

The Southwest Tasmania WHA was dedicated in late 1982, amidst enormous controversy which put the constitutional powers of the Australian Commonwealth Government to the test, and also brought the area into the limelight throughout Australia and internationally. Mt. Field National Park, the best available control site, has been a protected area for much longer and has a generally uncontroversial history. It is very much smaller, only $1.2 \%$ the area of the WHA, but it received almost one-third as many visitors: over 23 times as many visitors per unit area.

Shark Bay is a large embayment half way up the arid west coast of Western Australia. For many years it has been famous for the dolphins of Monkey Mia, which swim into the shallows amongst tourists. Historically, tourists could also feed and touch the dolphins, though these practices have now been greatly curtailed because of concerns over the dolphins' health. Ningaloo Marine Park is a little further north on the same coastline, offshore from Cape Range National Park. It is known for its coral reefs, and for the opportunity to snorkel with whale sharks during April, May and June. It is about one-fifth the size of Shark Bay WHA, which was listed in 1991.

The Central Eastern Rainforest Reserves Australia (CERRA) WHA consists of a set of discrete national parks and other reserves in northeastern New South Wales (NSW) and southeastern Queensland (Qld), which together contain most of the remaining rainforest remnants of subtropical eastern Australia. The forests of southwestern Western Australia, (SW-WA) used as a control, are temperate rather than subtropical, and extend through a series of parks and forests, variously used for logging, recreation and conservation. The total area of the national 
parks in SW-WA is about one-quarter that of the CERRA reserves. Visitor numbers are recorded differently: the SW-WA parks currently receive about 60,000 visitor-days annually, as compared to approximately 520,000 visitors annually for CERRA.

\section{Data sources}

For all these sites, we collected data on total visitor numbers and the relative proportions of domestic and international visitors, from a wide variety of sources, for as many years as available. These sources include: reports from government environment agencies (e.g. AHRSEC, 1973; Environment Australia, 2000; Hardy, 2001) and international agencies (e.g. WCMC, 1995-2000); reports from universities, consultants, and non-government organisations (e.g. ESS, 1994; FIDO, 2001; Ward, 1999); park management plans, parks-agency databases and personal communications from parks staff. In all, data were obtained from over 100 written sources and 24 individual experts (Buckley, 2002). In total, we were able to obtain almost 1000 data points on total, domestic or international visitor numbers at particular sites in particular years. We compiled these as site-by-site graphs. Where raw data suffered from minor deficiencies such as missing months or subsites, we made appropriate adjustments by reference to other years. For larger disparities such as different data sources, we examined each source independently. No attempt was made to smooth or standardise graphs.

\section{Results and Discussion}

\section{Fraser Island}

Intermittent data on total visitor numbers to Fraser Island are available since 1970, with annual data available since 1986. There has been a steady and approximately linear grow th in total visitor numbers, at a rate around 12,500 visitors per

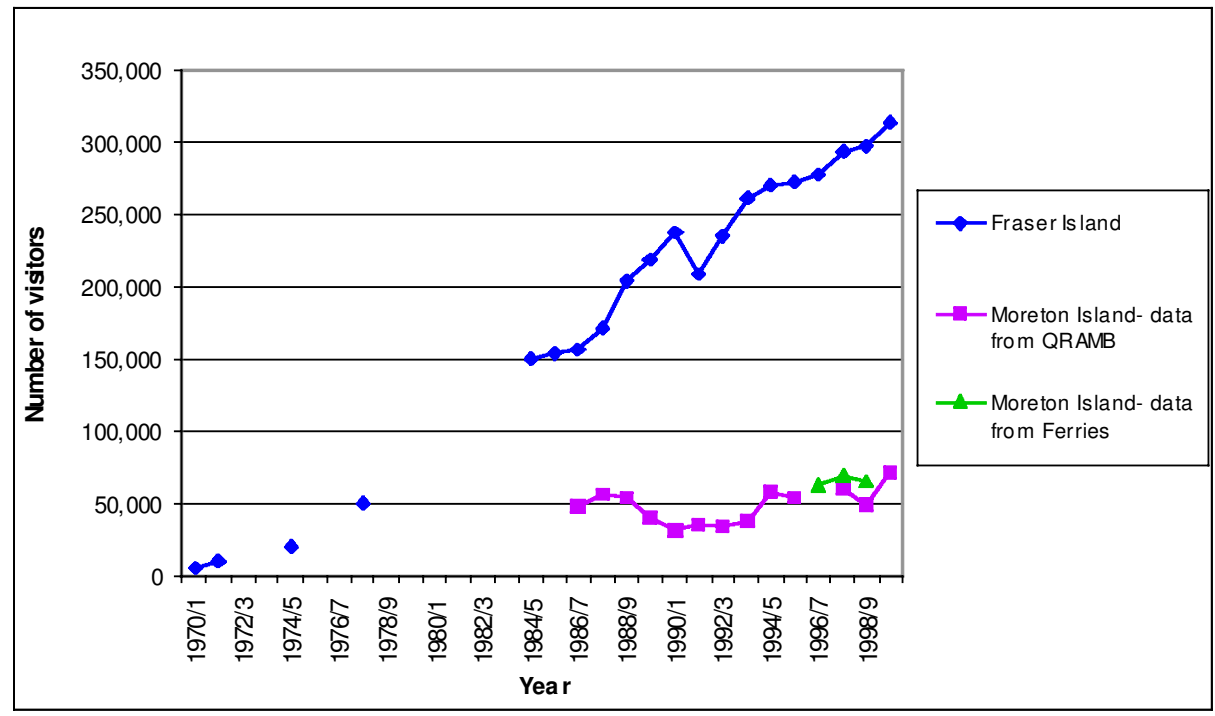

Figure 1 Total visitor numbers, Fraser Island WHA and Moreton Island NP 


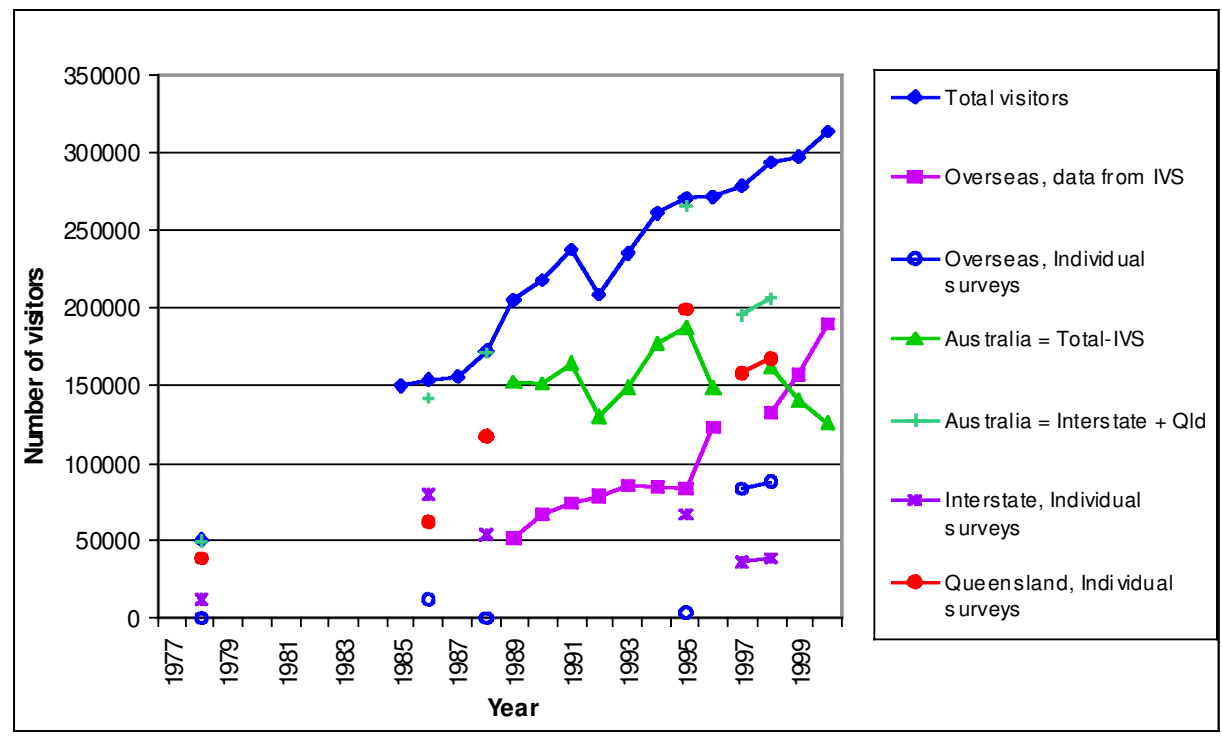

Figure 2 Visitor origins, Fraser Island

year (Table 1, Fig. 1), but with no significant change in this rate of growth at or around the listing date. Over the same period, total visitor numbers at Moreton Island have fluctuated but have not grown significantly. There are various sources of data for the proportion of overseas visitors at Fraser Island, but they are conflicting. In particular, numbers reported by the International Visitor Survey (IVS) are three times as high as those derived from on-ground surveys in the same years (Fig. 2). Both these sources of data indicate that the proportion of international visitors has grown over time, but neither is adequate to detect any possible effect of World Heritage listing. At Moreton Island there are very few international visitors.

Fraser Island is currently a very well-known destination for international visitors to Australia, much more so than Moreton Island. Recent growth in the number of overseas visitors seems to be simply as a well-known tourist attraction, with the controversies of the past now reduced to part of the interpretation programmes. Historically, however, it seems to have been these environmental controversies, and notably the efforts of organisations such as the Fraser Island Defenders Organisation, which first drew international attention to the value and plight of the tall forests, and triggered the growth in international nature tourism as an addition to domestic recreational fishing. World Heritage listing was one of the outcomes of this controversy, and the growth in visitor numbers and international visitors seems to have started at the time of the controversy rather than the time of listing.

\section{Kakadu}

For Kakadu, intermittent data on total visitor numbers are available before 1982 , and annual data since 1982. There are no data on the proportion of overseas visitors prior to 1982. A number of local on-ground surveys were carried out 


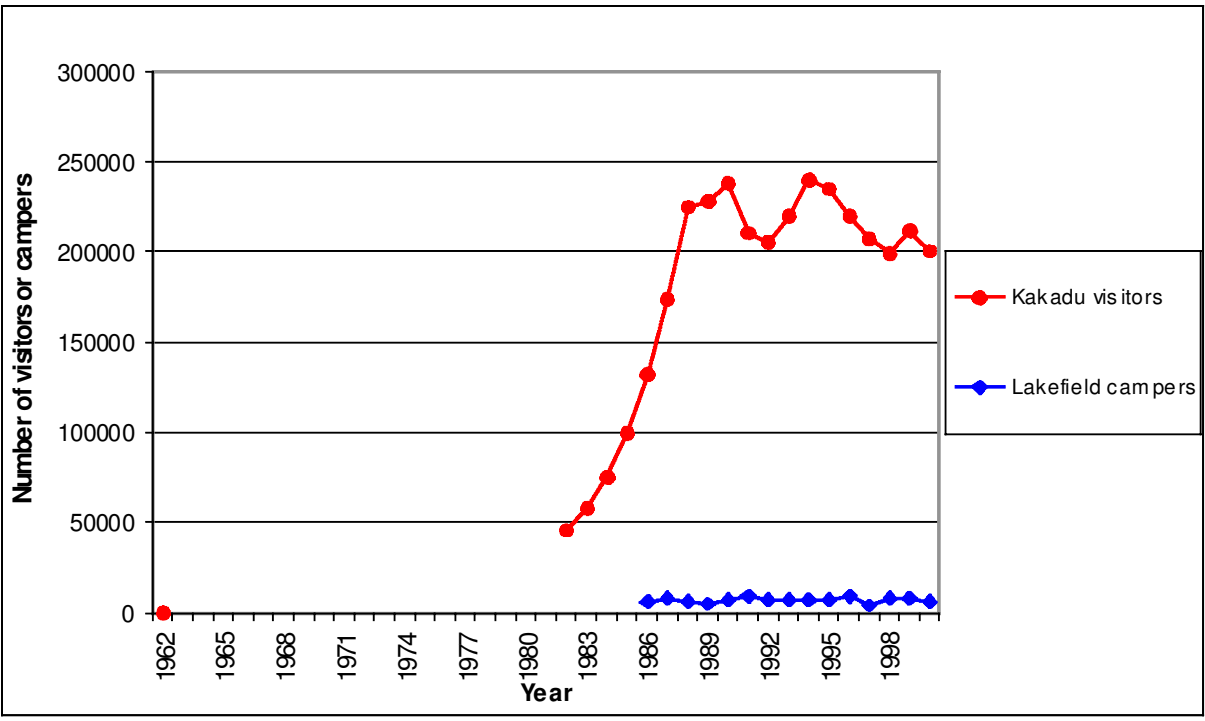

Figure 3 Total visitor numbers, Kakadu WHA and Lakefield NP

between 1982 and 1990, and data from the IVS are available annually from 1989 to 2000. Unlike Fraser Island, figures from the IVS at Kakadu do seem to match those from on-ground surveys. Historically, Queensland parks did not record total visitor numbers, but only those applying for camping permits. Prior to Stage 1 listing in 1981 total visitor numbers were relatively low, less than 50,000 per annum. Between Stage 1 and Stage 2 listing, visitor numbers grew considerably, increasing by four times in five years (Table 1, Fig. 3). The pre-1982 data, however, are too patchy to determine whether there was a statistically significant change at Stage 1 listing, or simply a continuing exponential growth. During the period between Stage 1 and Stage 2 listing at Kakadu, there was intense and widespread political controversy over the likely environmental and cultural impacts of mining in the area. There was also conflict, in international fora, between the Commonwealth and Northern Territory governments of the time.

Following Stage 2 listing, growth in visitor numbers was abruptly truncated, and numbers remained stable for the following 13 years, with a slight dip prior to Stage 3 listing and a slight increase subsequently. The number of campers at Lakefield also remained stable since Stage 2 listing for Kakadu, with minor fluctuations matching those at Kakadu. The latter, including those at Stage 3 listing, were therefore presumably due to external factors at a regional or larger scale. There are no figures from Lakefield for the period corresponding to rapid growth between Stage 1 and Stage 2 listing at Kakadu. The proportion of international visitors at Kakadu has increased steadily from 10\% in 1982 to $50 \%$ in 2000, with some fluctuations in the years immediately following Stage 2 listing (Table 1, Fig. 4). There are fewer international visitors amongst the campers at Lakefield, but the proportion has also increased steadily, from around 3\% in 1986 to around 9\% in the late 1990s. 


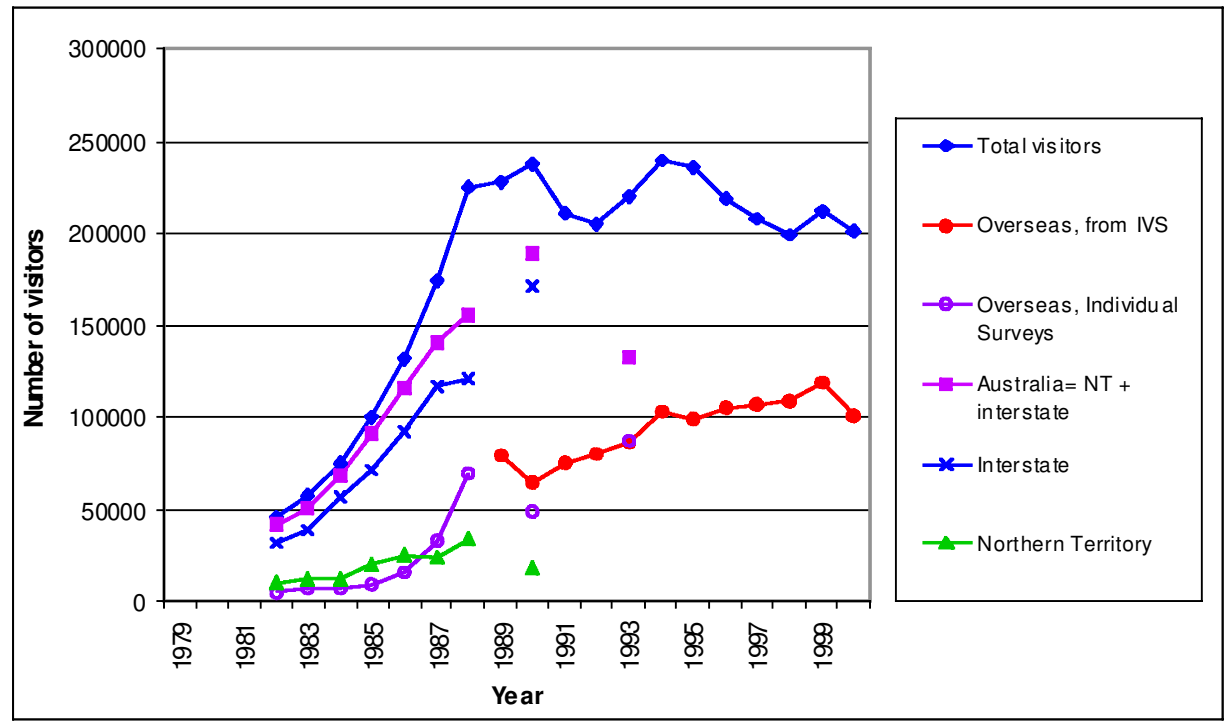

Figure 4 Visitor origins, Kakadu WHA

\section{Uluru-Kata Tjuta}

Data on total annual visitor numbers at Uluru are available since 1961. These are derived from a range of different but generally consistent sources. Historically, two phases can be discerned. From the 1960s until about 1984, there was a steady linear increase of around 4300 additional visitors each year, with the total doubling in 12 years. From 1984 to 1988 the rate of increase was much greater, with over 21,000 additional visitors each year, and the total doubling in five years (Fig. 5). This increased rate has been sustained, with linear growth continuing until 2000, at an average rate of around 17,500 additional visitors per year.

The period of increased growth, however, commenced in 1984, four years prior to World Heritage listing. Hence it was probably due to two factors: completion of upmarket tourist resort accommodation at Yulara Village and the conclusion of an agreement between the Australian Commonwealth Government and the Anangu Aboriginal People in 1985. This agreement followed considerable public debate and controversy over ownership and management. These factors seem to have had a more powerful influence on visitor numbers than the technical act of World Heritage listing. Indeed, visitor numbers fell briefly in 1989/90 immediately after listing. This, however, was almost certainly due to a pilots' strike in that year. Numbers also fell at Kakadu, for example, in 1989/90.

No data are available from Purnululu during the 1960s and the 1970s, the early slow-growth period at Uluru. During the later rapid-growth period at Uluru, the total number of on-ground visitors at Purnululu has increased steadily from close to zero in 1983, to around 17,000 in 1999 - a linear growth rate of approximately 1000 additional visitors each year.

Information on the proportion of international visitors at Uluru is available 


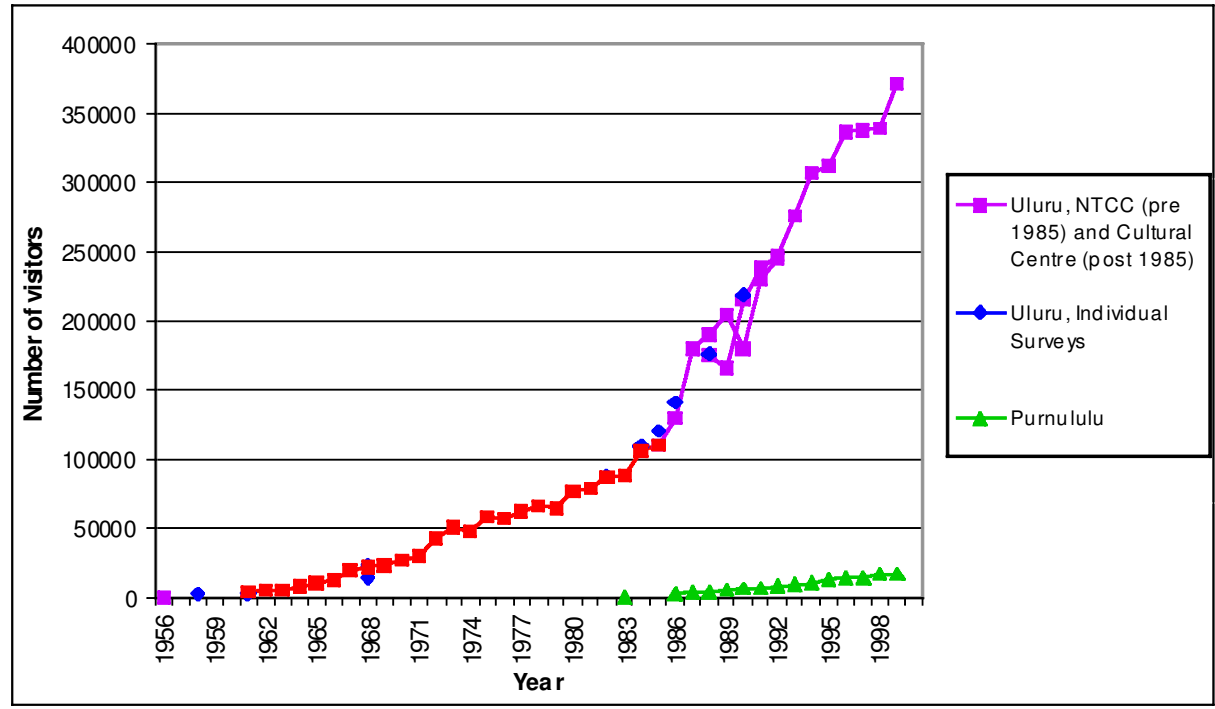

Figure 5 Total visitor numbers, Uluru - Kata Tjuta WHA and Purnululu NP

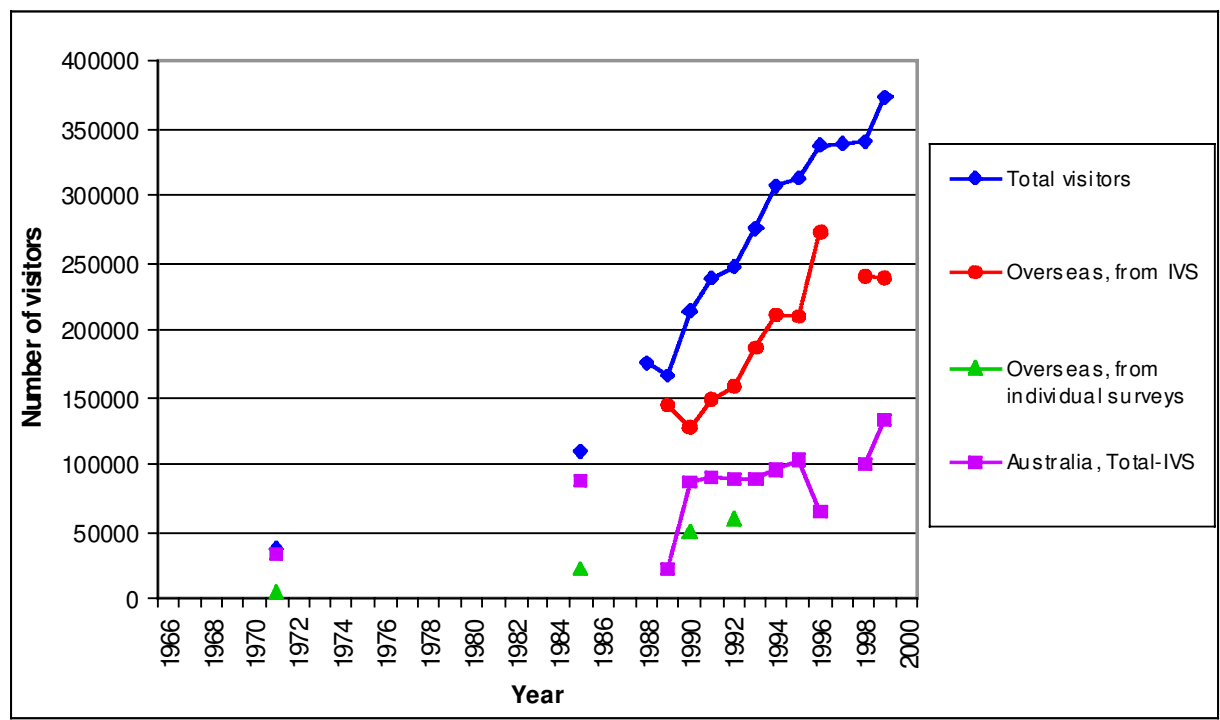

Figure 6 Visitor origins, Uluru - Kata Tjuta WHA

both from on-ground surveys and from the IVS, but the figures are very different (Table 1, Fig. 6). Only one year's data are available prior to listing, in 1971, so the effect of listing cannot be tested. Figures from the IVS indicate that the proportion of international visitors has increased over the period since listing; figures from on-ground surveys indicate that it has not. At Purnululu, international visitors made up $5 \%$ of the total in 1987 and $15-25 \%$ in 1999 and 2000. In the absence of 
any intermediate data, however, it is impossible to determine whether this represents a long-term trend.

\section{Southwest Tasmania, Shark Bay and CERRA}

For the Southwest Tasmania, Shark Bay and CERRA WHAs and their control sites, even fewer and less reliable data were available (Buckley, 2002). Results are summarised below but data are not presented in detail.

Data on visitor numbers to the Southwest Tasmania WHA are available since 1970, but only from individual subsites, and with some major gaps in the records, particularly around the date of listing. At some of these subsites (Lake St Clair and Marakoopa Cave), total visitor numbers grew more rapidly before listing than afterwards; whereas at others (Cradle Mountain), growth was more rapid after listing. Whilst it is clear that the total number of visitors to the WHA is growing significantly over time, the data are inadequate to detect any possible subsidiary trends during different time periods. Data are also available since 1970 for Mt Field NP. Though intermittent, they suggest that there has been little change in the total number of visitors throughout this entire period. During the 1970s, there were far more visitors to Mt Field than to the Southwest, presumably since it was far better known and far more accessible. During the late 1990s there have been many more visitors to the WHA, presumably since it is now at least as well known and accessible, and larger. The Tasmanian Visitor Survey provides annual data on the origins of visitors to various destinations in Tasmania, but it combines interstate and international visitors. At Cradle Mountain and Lake St Clair, this proportion fell from around 80\% in 1980 to around 50\% in 1990, and rose again to around $80 \%$ in 2000 . Data are hence inadequate to determine whether World Heritage listing had any effect on the proportion of international visitors.

Visitor numbers are available for Monkey Mia at Shark Bay WHA, and Cape Range NP at Ningaloo, since the late 1980s. Both show a slight long-term increase, but this is small compared to year-to-year fluctuations, due principally to factors such as cyclones. For the last three years, visitor numbers have been available for five separate subsites within Shark Bay WHA, but it seems likely that the same individual people visit each of the five subsites. The proportion of international visitors at Monkey Mia has been recorded annually since 1991 . During this period it has increased steadily by around 3\% per year, from $10 \%$ to $40 \%$. The proportion of international visitors at Ningaloo is only known for three years: $8 \%$ in $1991,32 \%$ in 1997 , and $36 \%$ in 2000 . Again, the same individual people may well visit Shark Bay and Ningaloo on the same trip. Overall, data from Shark Bay are insufficient to determine whether visitor numbers or origins were affected significantly by World Heritage listing, but the indications are that it was not.

Data on visitor numbers for the NSW subsites of CERRA are available for only six individual years in the period 1969-1998. Total numbers have increased over time, but patterns are not clear. The totals for the three years' data prior to WH listing are all lower than for the three years after listing, but the data are inadequate to distinguish whether this reflects a steady long-term growth, or an increase associated with listing. For the Queensland subsites of CERRA, a long time-series of annual data is available, but only for campers rather than total visi- 
tors. There does not seem to be any significant change at or around 1994, when the Queensland Parks were added to the CERRA WHA. Annual figures for total visitors to five individual national parks in southwest WA are available since 1992, but only patchy information before that. Two of the major destinations, Walpole-Nornalup and the Valley of the Giants, were closed to visitors in 1994 to 1997, for construction of visitor facilities. Historical information on the proportion of international visitors is apparently not available for the NSW parks in the CERRA WHA, or for the parks of southwest WA. In Lamington National Park in the Queensland portion of CERRA WHA, annual data on visitor origins are available for campers only, since 1986. During this period, the proportion of international visitors has increased steadily from $2 \%$ in 1986 to $12 \%$ in 1999 , an increase of around $0.77 \%$ per year. There is no indication that this rate of increase changed at or around 1994, when Lamington NP was added to the CERRA WHA.

\section{Conclusions}

The major conclusions from these results may be summarised as follows:

(1) Even for Australia's largest and best-known World Heritage Areas, past data on visitor numbers and origins are generally too incomplete to track historical trends except at the broadest scale.

(2) Control sites are valuable to differentiate the effects of external factors such as economic cycles and airline strikes, but the available control sites for Australia are too different from the WHAs to identify specific effects of World Heritage status by comparing the two.

(3) Most of the WHAs considered here received several times more visitors than the control sites, but it is not clear whether the difference is because the WHAs are larger or more accessible, because they are better-known, because they are listed as World Heritage, or because they contain features of natural or cultural heritage which the others do not.

(4) For those WHAs where distinct historical changes in the rate of growth of total visitor numbers can be discerned, the precise patterns and their relation to listing data differ between sites.

(5) The proportion of international visitors seems to have grown steadily since listing at all the WHAs studied. At some sites, however, it was already growing prior to WH listing; similar growth has also occurred at some of the control sites.

(6) In so far as can be determined from available data, any significant increases in the growth of visitor numbers at WHAs seems to have coincided more closely with periods of major environmental controversy rather than the date of WH listing as such, though there are too many other factors and inadequate data to establish this pattern definitively. If so, it seems that the tourism industry of today should be indebted to the conservation activists of the past not only for protecting one of their primary resources, but also for advertising it.

How do these results from Australia compare with World Heritage sites in other countries? For natural heritage in the USA, where visitor records are far 
more complete and comprehensive than in Australia (USNPS, 2000), the National Parks Service testified to Congress as follows (Galvin, 1997):

Rather than being harmful to local and community interests, World Heritage designation appears to be economically beneficial and a lure for foreign tourists. It correlates closely with increased visitation. During the period 1990-1995, visitation to U.S. World Heritage parks increased $9.4 \%$ as opposed to a $4.2 \%$ increase for all parks. There is evidence to suggest that a significant part of the increase is derived from increased international tourism; World Heritage designation makes it more likely that foreign visitors, especially those with specialised interests, will learn about and consider visiting these parks. For example, Wrangell-St. Elias National Park reports that an increase in foreign visitation from Europe, currently at $10 \%$, may be due to its World Heritage designation. Grand Canyon National Park, where foreign visitation is roughly $40 \%$, reports that foreign visitors respond more readily to the World Heritage designation than to the just the 'national park' term. Given that the total economic benefit of Grand Canyon to the surrounding region is estimated at $\$ 350$ to $\$ 700$ million per year, the impacts of the World Heritage designation is clearly salutary there.

For cultural heritage in the UK, however, Rodwell (2002) argues that: 'There is no proven relationship between World Heritage Site status and visitor numbers. For every site that has experienced an increase since inscription, another can be cited that discloses a decrease.'

The Australian results reported here are derived from a rather exhaustive search for historical data and it seems unlikely that uncertainty could be reduced significantly by further application of the historical revealed-preference approach. It can reliably be concluded only (1) that World Heritage sites, for whatever reasons, do receive large numbers of visitors (and their money) and (2) that World Heritage listing, perhaps including associated political controversy, does indeed seem to increase the proportion of international visitors (and their foreign exchange) to individual sites.

To find out just how important World Heritage designation may be for individual holiday travel decisions, therefore, there seems little choice but to fall back on a stated-preference approach, i.e. interviewing tourists and attempting to understand their decision processes.

The conclusions reached in this paper are specific to World Heritage sites in Australia. Clearly, it would be of interest to UNESCO, to individual countries, to tourism organisations and to protected area management agencies to determine whether similar conclusions apply worldwide. At present, this is difficult to assess because many countries do not collect visitor statistics for their WHAs or other protected areas. There could well be a role for UNESCO in encouraging collection and analysis of such data globally, perhaps with assistance to countries whose own protected area agencies are ill equipped for the task.

\section{Acknowledgements}

This project was funded by the Australian Heritage Commission and the Cooperative Research Centre for Sustainable Tourism. Data were compiled by 
Boyd Blackwell and figures by Kelly O'Halloran. Assistance from Meg Switzer of AHC and Clem Tisdell of the University of Queensland is acknowledge with thanks.

\section{Correspondence}

Any correspondence should be directed to Dr Ralf C. Buckley, The International Centre for Ecotourism Research, Griffiths University, Gold Coast Campus PMB 50, Gold Coast Mail Centre, Queensland 9726, Australia (r.buckley@ mailbox.gu.edu.au).

\section{References}

Australia, House of Representatives Standing Committee on Environment and Conservation (1973) Report on Ayres Rock - Mount Olga National Park. Canberra: AGPS.

Buckley, R.C. (2002) World Heritage Icon Value. Canberra: Australian Heritage Commission.

Bureau of Tourism Research (2003) Australian Bureau of Tourism Research. On WWW at http://www.btr.gov.au. Accessed 15.1.03.

Environment Australia (2000) Australia's World Heritage properties. Environment Australia Online. On WWW at http://www.environment.gov.au/heritage/awhag /whu/sites. Accessed 1.12.00.

Environment Science and Services (1994) Kakadu National Park 1993 Visitor Survey. Spring Hill: ES\&S.

Fraser Island Defenders Organisation (2001) Values of Fraser Island tourism. On WWW at http:/ / www.fido.org.au/values-of-fraser-tourism.html. Accessed 1.12.00.

Galvin, D. (1997) Testimony on H.R. 901, 'The American Land Sovereignty Protection Act,' to US 105th Congress House of Representatives Committee on Resources, Washington, DC, 10 June.

Hardy, A.M. (ed.) (2001) Terrestrial Protected Areas in Australia: 2000 Summary Statistics from the Collaborative Australian Protected Areas Database (CAPAD). Canberra: Environment Australia.

Loomis, J.B. and Walsh, R.G. (1997) Recreation Economic Decisions: Comparing Costs and Benefits. Philadelphia: Venture Publishing.

Moisey, N. (2002) The economics of tourism in national parks and protected areas. In P.F.J. Eagles and S.F. McCool (eds) Tourism in National Parks and Protected Areas (pp. 235-53). Wallingford: CAB International.

Rodwell, D. (2002) The World Heritage Convention and the exemplary management of complex heritage sites. Journal of Architectural Conservation 3, 40-60.

UNESCO (1972) Convention concerning the protection of the world cultural and natural heritage. UNESCO, Paris. On WWW at http://whc.unesco.org/world_hc.htm. Accessed 15.1.03.

UNESCO (1998) Operational guidelines for the implementation of the World Heritage Convention. UNESCO, Paris. On WWW at http://whc/unesco.org/opgu.htm. Accessed 15.12.03.

UNESCO (2000) Explanatory Notes. Annex VIII, Report of the 24th Session of the World Heritage Committee, WHC-2000/CONF.204/21. Paris: UNESCO.

United States National Park Service (2000) Public Use Data Collecting and Reporting Program. Directors Order 82, 1 March 2000. Washington DC: USNPS.

Ward, J. (1999) The Calculation of the Recreational Use Value of a Queensland National Parkfrom Existing Data: Fraser Island a Test Case. Report to Queensland Tourist and Travel Corporation, Brisbane.

World Conservation Monitoring Centre (1995-2000) Natural site data sheets. WCMC, Cambridge. On WWW at http://www.wcmc.org.uk/protected_areas/data/wh. Accessed 1.12.00. 